\title{
Essential of Motor Performance Among 7-Year-Old Students in Terengganu: A Comparison Against Gender and BMI Using Machine Learning
}

\author{
N A Nawi ${ }^{1}$, M R Abdullah ${ }^{2 *}$, A B H M Maliki² and Faiza Renaldi ${ }^{3}$
}

\author{
${ }^{1}$ Faculty of Applied Science Social University of Sultan Zainal Abidin, 21300 University of Sultan Zainal Abidin, Gong \\ Badak Campus, Terengganu, Malaysia. \\ ${ }^{2}$ East Coast Environment Research Institute, 21300 University of Sultan Zainal Abidin, Gong Badak Campus, \\ Terengganu, Malaysia. \\ ${ }^{3}$ Informatics Department, Universities Jenderal Achmad Yani, Bandung Barat, Indonesia. \\ *Corresponding author. E-mail: razali896@yahoo.com
}

\begin{abstract}
This research is designed to make a comparison against gender and BMI in motor skill component among 7 years old student in Terengganu using Machine Learning. The motor skills can be further divided into two subgroups which are locomotive skills such as running, jumping, sliding and swimming and object-control skills such as tossing, catching and kicking. Typically, children develop certain motor skills at specific ages but not every child will reach milestone precisely at the same time because of the BMI. The objective of this study is to i) To identify the differences of leg muscle power, speed and coordination against gender and BMI and ii) To predict BMI group classification based on gender. A total of 4698 students were randomly chosen from primary schools in Terengganu with the mean weight $( \pm 22.49)$, height $( \pm 118.96)$, and BMI $( \pm 15.75)$. The total comprise students comprise of 2270 female students and 2427 female students. The independent variables for this study are gender and BMI meanwhile for dependent variables are power, coordination and speed. The study sample were tested by using MANOVA and machine learning. Result for MANOVA shows that only one variable shows the significant difference $p<0.05$ which is power. From the machine learning researcher can predict BMI group misclassification based on gender. From this study, we can help the parents to monitor their children nutrition and number of children's physical activities that will affect their motor performance.
\end{abstract}

Keywords: BMI, Comparison, Motor skills, Physical activities

\section{INTRODUCTION}

The Body Mass Index (BMI) is a physical calculation used to estimate the actual amount of body fat present in an individual and it is a tool used to assess and monitor changes in body weight [1]. BMI provides a simplified numerical indicator of an individual's thickness or thinness, that enabling the healthcare professionals to address weight issues with their patients more accurately [2]. A common use of the BMI is to determine how much the body weight of an individual departs from that which is natural or appropriate for the height of a person. There are five categories in BMI which are severe thinness, thinness, normal, overweight and obese [3]. For children, BMI is used differently [4].This is measured in the same way as it is for adults, but instead contrasted with the usual values for other same-age children. The BMI is compared with percentiles for children of the same sex and age 
instead of comparing to fixed thresholds for underweight and overweight [5].

Along with the BMI, a motor performance is a learned ability with absolute confidence to generate a predetermined result of motion [6]. The aim of motor performance is to maximize the ability to perform the skill at the rate of success, precision and to reduce the output energy consumption needed [7]. Motor performance are movements and actions of the muscles. It requires the use of large muscle groups to perform activities such as walking, balancing and crawling. Part of the development of these skills takes place in early childhood. The motor performance can be further divided into two subgroups which are locomotive skills such as running, jumping, sliding and swimming and object-control skills such as tossing, catching and kicking [8].

Motor-skill-related fitness refers to the ability to learn and develop basic physical skills [9]. These skills can be put into six categories which are agility, flexibility, coordination, power and speed. Typically, children develop certain motor skills at specific ages but not every child will reach milestone at precisely the same time because of the BMI [10]. Research has found that the prevalence of children obesity and overweight is increasing and had been a problem worldwide [11]. Children with a higher level of BMI are usually at a higher risk of obesity-associated negative health problems [12]. This will frequently impact their quality of life, which also leads to increased long-term morbidity and a reduced in life expectancy. Nonetheless, children that have higher level BMI and lower level BMI have poorer appearance, sport competence and overall physical self-concept despite not being less healthy, physically active, or strong [13]

Besides, motor performance is an important part of developing a child [14].Gross and fine motor performance practice to make more complexity of movement necessary to engage in many sports and physical activities [15]. Good motor performance in children were associated with increased physical activity, enhanced cardiorespiratory health and a better classification of weight. The condition of children's motor performance will predict the outcome of potential injury and lower fitness levels [16]. Delays in the development of motor skills can cause health problems. Children who are unable to operate the role of motor development are assessed from two factors, namely intrinsic factor and extrinsic factors. Examples of intrinsic factors are age and gender, while extrinsic factors are training and learning, and lifestyle.

\section{METHODOLOGY}

\subsection{Area of study}

This study examined Terengganu Physical Fitness among 7 years old. Systematic random sampling requires a complete sampling system and the correct techniques used in this research. 56 schools were selected. The school selection was made by listing all schools in Terengganu, which are 352 primary schools were listed and then 56 schools were randomly selected. By listing all the 56 selected schools, the researchers conducted test on 7 years old children.

\subsection{Participating and testing procedure}

The sample size in this study is 4698. This study used random sampling where 7 years old children from various of primary school in Terengganu. The anthropometric measurement and motor performance data in this study were obtained from 2428 male and 2270 female of 7 years old children from all districts in Terengganu. Several anthropometric components are tested (weight, height, and BMI) and three motor subscales are tested which are power, coordination and speed.

Procedure for children anthropometric measurements and motor fitness tests were performed as follows. Parents, guardians, school administrators, and participants are granted this type of consent to clarify certain issues like study methods, research goals, and others. Participants agreeing to participate must voluntarily assist in data collection research. Within the consent form some main parts that participants must fulfill include personal data of participants and contact details; emergency contact information; health information and parent consent confirmation. This information is only available for research purposes. The researcher shall not reveal all personal information.

\subsection{Anthropometrics}

The instruments used are like a stadiometer and a weighing scale for a basic weight and height calculation [17] . The height feature was calibrated to the nearest 0.1 $\mathrm{cm}$ and the mass feature was calibrated in $\mathrm{kg}$. The height is determined by the foot to the head while standing on the flat wall with the rear position and the arms plied with the palms facing the investigator. The appropriate tool is the stadiometer. 


\subsection{Standing broad jump}

The participants will stand behind a line with feet slightly divided on the field. A two-footer departure and landing were used with the arms swinging back and the knees bent rhythmically to about 90 degrees forward. The participants must try to leap to their feet without falling backward. This test (SJB) would be canceled if the participants make the error that is double jumping, before jumping. Three trials were permitted and the most far-flung considerations were taken.

\subsection{Hand wall toss}

The gap between the markers is about 1 meter from the ground. Participants will stand erect behind a marker line, facing the wall. Through making an underarm motion against the wall and attempting to catch the ball with the opposite hand, the ball is thrown by one hand. The ball is then tossed back to the wall and first-hand caught. For 10 tries, this test continues. The number of throws caught will be recorded.

\subsection{Twenty-Meter Speed Test (20MR)}

Participants with reported opportunity running a single maximum sprint over a set range. The gap from start to finish was 20 meters. Once either foot crossed the starting point, time started to count and when either foot reached the finishing point. Before the experiment, participants must ensure that the starting position is consistent without any movement, beginning from a stationary position with a foot back to the foundation. The time to run each split distance (20 meters) was measured using a stopwatch.

\section{STATISTICAL ANALYSIS}

\subsection{Multivariate of Variance (MANOVA)}

In this study, researchers used by Multiple Analysis of Variance Analysis (MANOVA) to compare between the gender and BMI. Next, a technique in machine learning were run to see the misclassification of BMI. The MANOVA enhances this analysis by taking multiple continuously dependent variables into account and bundles them into a weighted linear or composite combination. The MANOVA compares whether the newly established combination differs by each group or level of the independent variable. In this way, the MANOVA mainly checks whether a statistically significant amount of variance is explained in the dependent variable by the independent grouping variable.

\subsection{Machine learning}

Machine learning is a data analytics tool that automates the building of analytical models. The machine learning method is way easier to use, low costs and can analyze more specific data samples. Machine Learning will establish group prediction and differentiate the F-value from the group. Machine learning also will notify the researcher which kids have the potential to move from the actual group to the predicted group.

Table 1: Multivariate Tests ${ }^{\mathrm{a}}$

\begin{tabular}{|c|c|c|c|c|c|c|}
\hline Effect & & Value & $\mathrm{F}$ & Hypothesis df & Error df & Sig. \\
\hline \multirow[t]{4}{*}{ Intercept } & Pillai's Trace & 0.984 & $97479.777^{\mathrm{b}}$ & 3.000 & 4685.000 & 0.000 \\
\hline & Wilks' Lambda & 0.016 & $97479.777^{\mathrm{b}}$ & 3.000 & 4685.000 & 0.000 \\
\hline & Hotelling's Trace & 62.420 & $97479.777^{\mathrm{b}}$ & 3.000 & 4685.000 & 0.000 \\
\hline & Roy's Largest Root & 62.420 & $97479.777^{\mathrm{b}}$ & 3.000 & 4685.000 & 0.000 \\
\hline \multirow[t]{4}{*}{ ClassBMI } & Pillai's Trace & 0.050 & 19.873 & 12.000 & 14061.000 & 0.000 \\
\hline & Wilks' Lambda & 0.950 & 20.184 & 12.000 & 12395.636 & 0.000 \\
\hline & Hotelling's Trace & 0.052 & 20.452 & 12.000 & 14051.000 & 0.000 \\
\hline & Roy's Largest Root & 0.050 & $58.349^{c}$ & 4.000 & 4687.000 & 0.000 \\
\hline \multirow[t]{4}{*}{ Gender } & Pillai's Trace & 0.070 & $118.187^{\mathrm{b}}$ & 3.000 & 4685.000 & 0.000 \\
\hline & Wilks' Lambda & 0.930 & $118.187^{b}$ & 3.000 & 4685.000 & 0.000 \\
\hline & Hotelling's Trace & 0.076 & $118.187^{b}$ & 3.000 & 4685.000 & 0.000 \\
\hline & Roy's Largest Root & 0.076 & $118.187^{b}$ & 3.000 & 4685.000 & 0.000 \\
\hline \multirow[t]{4}{*}{ ClassBMI * Gender } & Pillai's Trace & 0.006 & 2.294 & 12.000 & 14061.000 & 0.007 \\
\hline & Wilks' Lambda & 0.994 & 2.295 & 12.000 & 12395.636 & 0.007 \\
\hline & Hotelling's Trace & 0.006 & 2.294 & 12.000 & 14051.000 & 0.007 \\
\hline & Roy's Largest Root & 0.003 & $4.075^{\mathrm{c}}$ & 4.000 & 4687.000 & 0.003 \\
\hline
\end{tabular}


Table 2. Test of Between-Subjects Effects

\begin{tabular}{|c|c|c|c|c|c|c|}
\hline Source & Dependent variables & $\begin{array}{l}\text { Type III Sum of } \\
\text { Squares }\end{array}$ & $\mathrm{df}$ & Mean Square & $\mathrm{F}$ & Sig. \\
\hline \multirow[t]{3}{*}{ Corrected Model } & Power $(\mathrm{cm})$ & $321269.212^{\mathrm{a}}$ & 9 & 35696.579 & 118.020 & 0.000 \\
\hline & Coordination (No.) & $3041.340^{\mathrm{b}}$ & 9 & 337.927 & 46.965 & 0.000 \\
\hline & Speed (sec) & $258.355^{\mathrm{c}}$ & 9 & 28.706 & 91.592 & 0.000 \\
\hline \multirow[t]{3}{*}{ Intercept } & Power $(\mathrm{cm})$ & 15063854.60 & 1 & 15063854.60 & 49803.952 & 0.000 \\
\hline & Coordination (No.) & 28719.637 & 1 & 28719.637 & 3991.466 & 0.000 \\
\hline & Speed (sec) & 42517.839 & 1 & 42517.839 & 135660.30 & 0.000 \\
\hline \multirow[t]{3}{*}{ ClassBMI } & Power $(\mathrm{cm})$ & 56012.164 & 4 & 14003.041 & 46.297 & 0.000 \\
\hline & Coordination (No.) & 77.046 & 4 & 19.261 & 2.677 & 0.030 \\
\hline & Speed (sec) & 36.159 & 4 & 9.040 & 28.843 & 0.000 \\
\hline \multirow[t]{3}{*}{ Gender } & Power $(\mathrm{cm})$ & 69152.992 & 1 & 69152.992 & 228.633 & 0.000 \\
\hline & Coordination (No.) & 807.794 & 1 & 807.794 & 112.268 & 0.000 \\
\hline & Speed $(\mathrm{sec})$ & 69.997 & 1 & 69.997 & 223.338 & 0.000 \\
\hline \multirow[t]{3}{*}{ ClassBMI * Gender } & Power $(\mathrm{cm})$ & 4930.167 & 4 & 1232.542 & 4.075 & 0.003 \\
\hline & Coordination (No.) & 29.521 & 4 & 7.380 & 1.026 & 0.392 \\
\hline & Speed (sec) & 2.949 & 4 & 0.737 & 2.352 & 0.052 \\
\hline \multirow[t]{3}{*}{ Error } & Power $(\mathrm{cm})$ & 1417644.247 & 4687 & 302.463 & & \\
\hline & Coordination (No.) & 33724.183 & 4687 & 7.195 & & \\
\hline & Speed (sec) & 1468.971 & 4687 & 0.313 & & \\
\hline \multirow[t]{3}{*}{ Total } & Power $(\mathrm{cm})$ & 48178221.00 & 4697 & & & \\
\hline & Coordination (No.) & 128080.000 & 4697 & & & \\
\hline & Speed (sec) & 121695.954 & 4697 & & & \\
\hline \multirow[t]{3}{*}{ Corrected Total } & Power $(\mathrm{cm})$ & 1738913.459 & 4696 & & & \\
\hline & Coordination (No.) & 36765.523 & 4696 & & & \\
\hline & Speed (sec) & 1727.326 & 4696 & & & \\
\hline
\end{tabular}

\section{RESULTS AND DISCUSSION}

\subsection{The differences of leg muscle power, speed and coordination against gender and BMI among 7 years old students in Terengganu.}

The outcome of this study will explore the differences among studied sample which are carried out across variables (power, coordination and speed) with groups of genders (male and female) and BMI (severe thinness, thinness, normal, overweight and obese). Table 1 below shows Multivariate test for Pillai's Trace. The table shows that overall, there is a major impact on independent variable for class BMI $[\mathrm{F}(12,14061)=19.87, \mathrm{p}<0.5]$ and gender $[\mathrm{F}(3,4685)=118, \mathrm{p}<.05]$. The interaction effect class $\mathrm{BMI} *$ Gender $[\mathrm{F}(12,14061)=2.30, \mathrm{p}<.05)]$ that significant towards dependent variables (power, coordination and speed) in this study. Therefore, it can conclude that the power, coordination and speed was significantly dependent on gender and BMI.

Since the results of the analysis show that there is a major impact of the gender and BMI towards the dependent variables. However, the main effect of each dependent variable can be identified in the table 2 below that shows the Test of Between-Subjects Effects. Overall, the results in the table also shows that the main effect for Gender*BMI only significance on the power [F (4.08,
1232.542) $=4.075, \mathrm{p}<.05]$. Thus, gender and BMI are significantly differentiated by power.

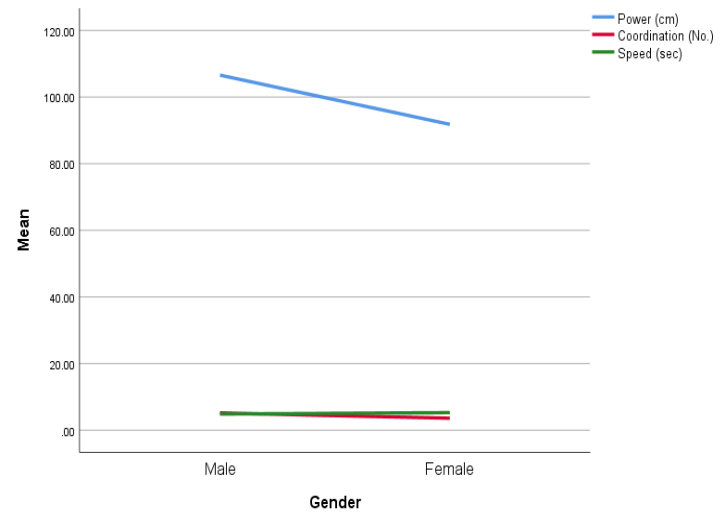

Figure 1. Line graph for mean difference for male and female

Line graph form for power, coordination, and speed female and male groups for have been shown in figure 1 below. From the graph, the line of power, coordination and speed counts higher on the left which is male and meanwhile for the line of power coordination and speed are counts lower for female on the right This figure has shown that male children are more active in physical activity than female children. On the other hand, figure 2 shows the line graph for BMI. The line shows that normal 
BMI counts as the higher score in power, coordination and speed and for the lowest score are obese. This is shown that the normal bmi children's are more active than the obese children.

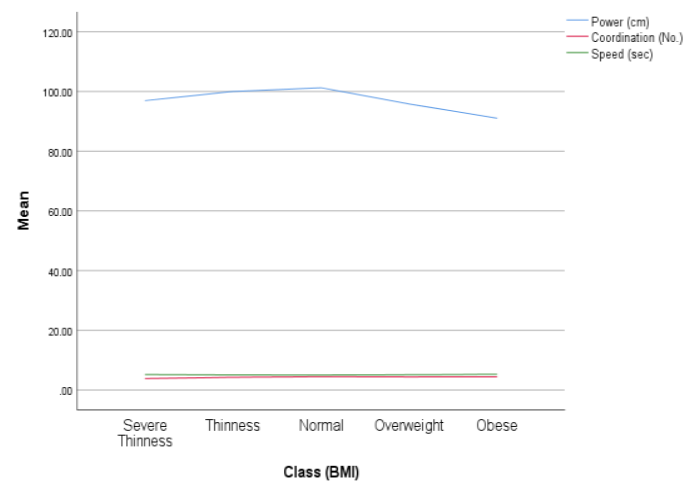

Figure 2. Line graph for mean difference for bmi classes

Predict BMI group classification among 7 years old students in Terengganu. The performance of these six processes of machine learning showed that $\mathrm{kNN}$, Tree, Random Forest, SVM, Neural Network and Naïve Bayes analyze a strong contrast between them. Therefore, Random Forest has the highest precision value which is 0.844 as shown in Table 3 below.

Table 3. Precisions value from machine learning

\begin{tabular}{lccccc}
\hline \multicolumn{1}{c}{ Model } & AUC & CA & F1 & Precision & Recall \\
\hline Knn & 0.865 & 0.726 & 0.677 & 0.688 & 0.726 \\
Tree & 0.948 & 0.801 & 0.789 & 0.797 & 0.901 \\
Random & & & & & \\
Forest & 0.975 & 0.831 & 0.809 & 0.844 & 0.831 \\
SVM & 0.52 & 0.414 & 0.456 & 0.531 & 0.414 \\
Neural & & & & & \\
Network & 0.616 & 0.696 & 0.573 & 0.581 & 0.696 \\
Naïve & & & & & \\
Bayes & 0.594 & 0.695 & 0.57 & 0.483 & 0.695 \\
\hline
\end{tabular}

In line with that, Table 4 below shows the confusion matrix group of cross-validation approaches using the machine learning process. The output applied for BMI which are severe thinness, thinness, normal, overweight and obese. The total correctly classified for normal class BMI is $81.0 \%$, obese $(87.0 \%)$, overweight $(91.0 \%)$, severe thinness $(91.4 \%)$ and thinness $(92.6 \%)$. The confusion matrix also allows the observation for misclassified in each BMI classes. For normal class BMI, obese (5.0\%), overweight $(2.5 \%)$, severe thinness $(2.9 \%)$ and thinness $(2.5 \%)$ are predicted to be in the same group.

The researchers managed to prove that there are significant differences of leg muscle power, speed and coordination against gender and BMI among 7 years old students in Terengganu using MANOVA and Machine Learning to monitor 7 years old children. This is consistent with the finding that boys are better than girls and both overweight and obese children are lower than average children [18]. In terms of motor performance, in all motto performance tests, boys received better results than girls. The effect of demographic and socio-cultural position can also be the difference. Socio-economic status, sibling and parents as having an impact on children and adolescents' physical activity [19]. It was indicated that girls participated in less intensive forms of physical activity whereas boys preferred more vigorous activity.

Table 4. confusion matrix group of cross-validation for BMI Predicted

\begin{tabular}{cccccccc}
\hline & & $\mathrm{N}$ & $\mathrm{Ob}$ & $\mathrm{Ov}$ & $\mathrm{Sv}$ & $\mathrm{T}$ & $\Sigma$ \\
\hline \multirow{4}{*}{$\mathrm{Actu}$} & $\mathrm{N}$ & $81.0 \%$ & $5.0 \%$ & $2.5 \%$ & $2.9 \%$ & $2.5 \%$ & 3264 \\
$\mathrm{al}$ & $\mathrm{Ob}$ & $6.0 \%$ & $87.0 \%$ & $3.5 \%$ & $5.7 \%$ & $1.2 \%$ & 512 \\
& $\mathrm{Ov}$ & $5.7 \%$ & $4.0 \%$ & $91.0 \%$ & $0.0 \%$ & $3.1 \%$ & 426 \\
& $\mathrm{~Sv}$ & $2.2 \%$ & $1.0 \%$ & $0.0 \%$ & $91.4 \%$ & $0.6 \%$ & 124 \\
& $\mathrm{~T}$ & $5.2 \%$ & $3.0 \%$ & $3.0 \%$ & $0.0 \%$ & $92.6 \%$ & 371 \\
& $\Sigma$ & 3998 & 301 & 201 & 35 & 162 & 4697 \\
\hline
\end{tabular}

Moreover, overweight and obese children often struggle to perform the difficult physical exercise which leads to less physical activity and less play [20]. These findings demonstrated the detrimental influence of obesity in children's everyday lives that obese children reported lower quality of life than average children in their own physical, mental, social, academic and quality of life [21].

\section{CONCLUSION}

The result for this study can help the parents to monitor their children nutrition, lifestyle and physical activities. Parents need to make sure their children physically active to gain the best motor skill. In the other hand, the kindergarten management need to provide playing facility at the kindergarten for the children to develop their motor skill at early childhood. This would also help to improve the development of motor performance among 7 years old [22]. Therefore, these models can decline the population of kids who have low development of motor performance. Moreover, the time and energy consumed can be reduced as it is much easier to have focused parameters or the ones which have been significantly proven.

\section{ACKNOWLEDGMENT}

University of Sultan Zainal Abidin (UniSZA) has cooperated with the National Sports Institute (ISN) and the National Sports Council of Terengganu with a view to gathering knowledge on children's physical health. Researchers are deeply thankful for their fruitful study engagement to parents, guardians, school officials and participants. 


\section{REFERENCES}

[1] T. I. Sørensen, P. Frederiksen, B. L. Heitmann. Levels and changes in body mass index decomposed into fat and fat-free mass index: relation to long-term all-cause mortality in the general population .International Journal of Obesity, 44 (10) (2020) 20922100 .

[2] A. M. Madden, S. Smith. Body composition and morphological assessment of nutritional status in adults: a review of anthropometric variables. Journal of human nutrition and dietetics, 29 (1) (2016) 7-25. DOI: https://doi.org/10.1111/jhn.12278

[3] S. Jalali Farahani, Y. S. Chin, P. Amiri, M. N. Mohd Taib. Body mass index (BMI) for age and health related quality of life (HRQOL) among high school students in T ehran. Child: care, health and development, 40 (5) (2014) 731-739. DOI: https://doi.org/10.1111/cch.1210 3

[4] W. Johnson, T. Norris, D. Bann, N. Cameron, J. K. Wells, T. J. Cole, R. Hardy. Differences in the relationship of weight to height, and thus the meaning of BMI, according to age, sex, and birth year cohort. Annals of Human Biology, 47 (2) (2020) 199-207. DOI: https://doi.org/10.1080/03014460.2020.1737731

[5] M. W. Gillman, S. L. Rifas Shiman, K. Kleinman, E. Oken, J. W. Rich Edwards, E. M. Taveras. Developmental origins of childhood overweight: potenti al public health impact. Obesity, 16 (7) (2008) 16511656. DOI: https://doi.org/10.1038/oby.2008.260

[6] D. A. Simon, R. A. Bjork. Metacognition in motor learning. Journal of Experimental Psychology: Learning ,Memory, and Cognition, 27 (4) (2001) 907. DOI: https: //doi.org/10.1037/0278-7393.27.4.907

[7] D. F. Stodden, J. D. Goodway, S. J. Langendorfer, M. A. Roberton, M. E. Rudisill, C. Garcia, L. E. Garcia. A developmental perspective on the role of motor skill competence in physical activity: An emergent relations hip. Quest, 60 (2) (2008) 290-306. DOI: https://doi.org/ $10.1080 / 00336297.2008 .10483582$

[8] A. Han, A. Fu, S. Cobley, R. H. Sanders. Effectiveness of exercise intervention on improving fundamental movement skills and motor coordination in overweight/obese children and adolescents: A systemat ic review. Journal of science and medicine in sport, 21
(1) (2018) 89-102. DOI: https://doi.org/10.1016/j.jsams .2017 .07 .001

[9] E. D’Hondt, B. Deforche, I. De Bourdeaudhuij, M. Lenoir. Relationship between motor skill and body mass index in 5-to 10-year-old children. Adapted Physical Activity Quarterly, 26 (1) (2009) 21-37. DOI: https://doi.org/10.1123/apaq.26.1.21

[10] J. M. Iverson. Developing language in a developing body: The relationship between motor development and language development. Journal of child language, 37 (2) (2010) 229. DOI: https://doi.org/ $10.1017 / \mathrm{S} 0305$ 000909990432

[11] P. T. James. Obesity: the worldwide epidemic. Clinics in dermatology, 22 (4) (2004) 276280. DOI: https://doi.org/10.1016/j.clindermatol.2004. 01.010

[12] R. R. Kipping, R. Jago, D. A. Lawlor. Obesity in children. Part 1: Epidemiology, measurement, risk factors, and screening. Bmj, 337(2008) 56. DOI: https:// doi.org/10.1136/bmj.a1824

[13] M. Morano, D. Colella, C. Robazza, L. Bortoli, L. Capranica. Physical self-perception and motor performance in normal-weight, overweight and obese children. Scandinavian journal of medicine \& science in sports, 21 (3) (2011) 465-473. DOI: https://doi.org/10.1 111/j.1600-0838.2009.01068.x

[14] E. Zachopoulou, A. Tsapakidou, V. Derri. The effects of a developmentally appropriate music and movement program on motor performance. Early Childhood Research Quarterly, 19 (4) (2004) 631-642. DOI: https://doi.org/10.1016/j.ecresq.2004.10.005

[15] L. L. Hardy, L. King, L. Farrell, R. Macniven, S. Howlett. Fundamental movement skills among Austra lian preschool children. Journal of science and medicine in sport, 13 (5) (2010) 503-508. DOI: https://doi.org/10 $.1016 /$ j.jsams.2009.05.010

[16] E. Vlahov, T. M. Baghurst, M. Mwavita. Preschool motor development predicting high school healthrelated physical fitness: a prospective study. Perceptual and motor skills, 119 (1) (2014) 279-291. DOI: https:// doi.org/10.2466/10.25.PMS.119c16z8 
[17] E. I. Rabito, G. B. Vannucchi, V. M. M. Suen, L. L. Castilho Neto, J. S. Marchini. Weight and height prediction of immobilized patients. Revista de Nutrição ,19 (6) (2006) 655-661. DOI: https://doi.org/10.1590/S $1415-52732006000600002$

[18] V. H. Wang, J. Min, H. Xue, S. Du, F. Xu, H. Wang, Y. Wang. What factors may contribute to sex differences in childhood obesity prevalence in China?. Public health nutrition, 21 (11) (2018) 20562064. DOI: https://doi.org/10.1017/S13689800180002

90

[19] S. W. Logan, L. E. Robinson, M. E. Rudisill, D. D. Wadsworth, M. Morera. The comparison of school-age children's performance on two motor assessments: the Test of Gross Motor Development and the Movement Assessment Battery for Children. Physical Education and Sport Pedagogy, 19 (1) (2014) 48-59. DOI: https://doi.org/10.1080/17408989.2012.726979

[20] Z. Shi, N. Lien, B. N. Kumar, G. HolmboeOttesen. Physical activity and associated sociodemographic factors among school adolescents in Jiangsu Province, China. Preventive medicine, 43 (3) (2006) 218-221. DOI: https://doi.org/10.1016/j.ypmed. 2006.04.017

[21] R. M. Puhl, K. M. King. Weight discrimination and bullying. Best practice \& research Clinical endocrinology \& metabolism, 27 (2) (2013) 117-127. DOI : https://doi.org/10.1016/j.beem.2012.12.002

[22] A. B. H. M. Maliki, M. R. Abdullah, A. Nadzmi, M. A. R. Zainoddin, I. M. Puspitasari, N. F. A. Jibril, S. K. S. Ali. Kids motor performances datasets. Data in brief, 34 (2021) 106582. DOI: https://doi.org/10.1016/j .dib.2020.106582 